\title{
Peculiarities of the Ukrainian Language as a Foreign Language Teaching in the Conditions of Distance Learning
}

\author{
Mariia Bilianska ${ }^{1,2}$ Alla Kolodyazhna ${ }^{1}$ Yana Shuhailo ${ }^{1, *}$ Lubov Bohoslavets $^{1}$ \\ ${ }^{1}$ Kyiv National University of Technologies and Design, Ukraine \\ ${ }^{2}$ National Pedagogical Dragomanov University, Ukraine \\ *Corresponding author.Email:shugaylo.yv@knutd.edu.ua
}

\begin{abstract}
The article analyses the experience of teaching Ukrainian as a Foreign language (UFL) in the conditions of distance learning in higher education institutions. An analysis of the scientific achievements of researchers in the field of teaching a foreign language, including UFL, is made. UFL is considered a mean of intercultural communication and the linguocultural and sociocultural knowledge acquisition tool. The results of the survey conducted among teachers of UFL on the use of online educational resources and the education system's readiness for distance learning (online) are summarised. The most popular online platforms and resources are identified in the paper. The main features of teachers and students activity in the distance learning process, its results and problems are outlined. It is concluded that distance learning allows participants to establish cooperation and two-way communication in the educational process. An important factor of successful language learning is the motivation of international students to learn the language, mastering self-education skills, direct contact with peers. The organization of art events, the involvement of listeners of the preparatory department and students to participate in scientific conferences held online facilitate it. Simultaneously, attention is focused on the problems and shortcomings of distance learning of UFL. The technical component needs to be improved, namely, equipping with the latest software, Internet and mobile communication access, forming skills to work online, and using basic computer programs (e-textbooks, video content, online tests, etc.).
\end{abstract}

Keywords: distant learning, Ukrainian language as foreign language, educational process, learning technologies, organization of classes.

\section{INTRODUCTION}

In today's world, the role of the mobility of students and teachers of higher education institutions is growing in the context of globalization. It expands the opportunities for training competitive professionals in the labour market, gaining and improving professional competence, experience exchange, self-realization of the individual, and expanding research potential. At the same time, higher education is characterized by internationalization cooperation at the level of higher education institutions, particular states and the educational space in general. "Internationalization of education is one of the factors of forming the global space of higher education. It is classified as external (international academic mobility) and internal (implementation of world standards, internationalization of learning courses, cross-cultural programs)" [1]. The conclusions of J. Knight are a clear confirmation of this: "Internationalization can be used as a strategy to enhance the international, global, and intercultural dimensions of teaching and learning, research and knowledge production, and service to society" [2].

Researchers distinguish between concepts "mobile international students" and "foreign students" [1]. International students are those who are not citizens of Ukraine and are identified by citizenship/nationality. According to the Ukrainian State Center for International Education of the Ministry of Education and Science of Ukraine, in 2019 80,470 international students studied in Ukraine, mostly from India, Morocco, Azerbaijan, Turkmenistan, Nigeria, Turkey, 
China, Egypt, Israel and Uzbekistan. Among them, 6,949 people studied at the Preparatory Courses, or $8.64 \%$ [3]

In international students teaching, it is essential to form not only specific competencies that allow them to participate in intercultural communication, but also to promote the acquisition of linguocultural and sociocultural knowledge. When teaching UFL the peculiarities of national educational systems of native countries and languages of students, psychological characteristics of representatives of different nationalities are taken into account, which promotes cross-cultural interaction. It necessitates planning individual educational trajectory, improvement, optimization and implementation of techniques, methods, and means of learning to increase students' motivation.

The purpose of the study was to generalize the experience of learning the Ukrainian language as a Foreign language and highlight the advantages and disadvantages of its teaching in distance mode.

To achieve this goal, various research methods were used: the survey - to determine the advantages and disadvantages of teaching the Ukrainian language as a Foreign language in distance learning; ranking allowed to organize the factors in descending order of its importance; comparison - to study various scientific views on the problem; systematization and generalization - to formulate conclusions. The information-factual and methodological basis of the research were the publications of Ukrainian and foreign scientists, Internet resources, the results of the authors' research. The research was based on general scientific methodological approaches - system and competence.

In research on foreign language learning, scientists have focused on the problems of mobile learning (Mlearning), e-learning (E-learning). Evidence of this is the emphasis on learning English as a foreign language using mobile devices - smartphones, tablets, mobile phones - in educational institutions in Taiwan [4], Thailand [5], Saudi Arabia [6], [7].

Researchers have also explored the possibility of using mobile devices to exchange information regardless of the location of users and time. In order to increase students' motivation to learn the language [4], [8] were developed mobile applications for vocabulary enrichment. The effectiveness of their use, in particular, the positive effect on the self-study of language was investigated. O. Suwantarathip, and W. Orawiwatnakul [8] proved the positive influence of performing vocabulary exercises with the help of
SMS messages. At the same time, Angvarrah Lieungnapar [5] recommends combining modern technologies, including mobile applications, with traditional language learning methods. Communication with native speakers in the process of real dialogue, as well as the use of cognitive games, were provided to increase the motivation of students.

To increase motivation to learn English as a Foreign language, B. Zou and J. Li [9] proposed using such types of tasks as listening, reading, vocabulary enrichment and conversational topics both during classroom work, and independent extracurricular learning. According to the survey, $70 \%$ of respondents have increased the motivation to enrich their vocabulary during self-study through mobile devices. Besides, devices allow listening and reading texts, practice the correct pronunciation.

The results of the research on the application of the didactic possibilities of animated films [10], as well as news and films are important [11], as an original audio material in the process of second foreign language learning. Pedagogical efficiency and value of audiovisual sources compared with printed materials are proved, for example, cartoons reviewing. The use of animation promotes interest in learning a foreign language, increases the students' cognitive activity, stimulates them to discuss and participate in the discussion of the content of the TV programs. The use of animation is justified on the basis of constructivism - a social approach to learning, which involves the acquisition of knowledge by students from the environment in the research process: "Constructivism is a social-based teaching approach that encourages learners to construct knowledge from the surrounding social context throughout a process of investigation. Concerning the concept of a cartoon, it works as an incentive tool that enhances learners' social involvement within both collaborative discussion and the content of animated film" [10]. For second language learning as a source of authentic language input is also used interactive TV, allowing students to create their learning trajectory, choose the material they like, and view it in an informal setting. Such sources can be games, plays, shows, comedies [12].

Z.O. Pakholok, L.P. Myroniuk [13] proposed a motivated model of presentation and its creation in Google Slides in the process of learning UFL. This service was chosen because it is easy to use, free, allows students to work from any device. It is also possible to place the created materials on a web page, as well as access and edit them via the Internet, regardless of which device users are working on. The integration of various Google applications made it 
possible to create a site using Google Sites to host presentations about the international students' home countries. This provided access to local lore information in Ukrainian to a wide range of users. The proximate perspective is to fill the site with works of students with the possibility of recording the final stage of knowledge assessment in the discipline UFL.

To increase cognitive interest in learning UFL, researchers [14] use the interactive methods, in particular, the methods of project design and case method. The results of project activity are recommended to present with the help of PowerPoint presentations: "My hometown", "Nature of my homeland", "National costume", "My Ukrainian friends", "Virtual tour of the cities of the world", etc. The topics of the projects are country studies oriented, for example: "Banking system of Ukraine", "Monetary system of my country", "Natural resources of my homeland", "Climate of my country". The application of the case method (the method of situational exercises) has a practical focus on choosing a future profession. The effectiveness of interactive methods correlates with the general focus of modern higher education institutions on a competency-based approach to learning. International students are offered tasks, the result of which is the solution of specific business situations in the economic, construction, oil and gas and other industries [14].

Noteworthy is the method of mastering the material, aimed at developing skills of dialogic speech during the study of the course UFL. L. Sheremeta [15] describes an optimal selection of the ways to increase the effectiveness of the classes in the process of Ukrainian language learning. Dialogue speech is important for international students, as it helps to communicate both in everyday life in the Ukrainianspeaking environment, and optimizes the studying of international students in higher education institutions of Ukraine [15].

The experience of teaching UFL at the preparatory department of the Kyiv National University of Technology and Design (KNUTD) is aimed at ensuring complete adaptation of international students to new ethnocultural and linguistic situations that may arise in the study of specialized disciplines. A sufficient level of proficiency in the Ukrainian language will allow an international student to master the professional disciplines' programs fully. The developed course training programs are scientifically substantiated, logically constructed and provide knowledge of the language and methods of its teaching. Programs also popularise Ukrainian culture, Ukrainian traditions, which encourages the development of patriotic feelings, personality formation. Teaching UFL in KNUTD meets the requirements of the time, based on modern achievements in science and technology. Students use Internet resources to search for additional information on the topic being studied. In order to check the level of knowledge of students during practical classes, various online tests are used. Students are taught to use online dictionaries. A positive result during the formation of dialogic speech has the use of interactive teaching methods ("Incomplete sentences", "Brainstorming"), as well as didactic games. The learning of the UFL with the help of the proposed methods effectively influences the development of international students' creative abilities [16].

In the research of scientists, a special place is occupied by the problem of studying the motivation to learn a language. Among the main motives that stimulate to master English as a foreign language, are intrinsic interest (optimal degree of the challenge) and arousal of curiosity), mastery (i.e. the feeling of competence), the perceived value of activity (personal relevance), affective states (i.e. confidence), attitudes to the target language, attitude to the English learning, attitude to the target language community and culture, cultural norms, the local education system, the nature and amount of appropriate praise and rewards, mediated learning experiences, peers factor [17]. A. Kolodyazhna concluded that it is necessary to stimulate self-development and self-improvement of students of the preparatory department, which aims to help in career guidance and choice of future profession, in further professional development and career growth. Emphasis is made on the formation of internal motives in the study of the Ukrainian language, associated with the satisfaction from the acquired knowledge and the ability to use them, namely the formation of language competence. In this regard, among the methods and techniques of teaching UFL are conversations about the profession, professional qualities of the individual, the criteria of professionalism for the conscious choice of future profession by students and focusing on achieving results of their activities [18].

\section{METHODS}

The research was conducted at the end of 2020 by an anonymous survey of teachers of UFL (14 people), including the Kyiv National University of Technology and Design (KNUTD) (10 people), "Open International University of Human Development "Ukraine" (2 persons) and the National Aviation University (NAU) (2 persons). The questionnaire 
contained 14 questions, both closed-ended and openended. Open-ended questions allowed the respondents to express an opinion on the problems they faced in the transition to distance learning. In each closed-ended question were offered several answer options, among which respondents had the opportunity to make a choice.

All questions can be grouped into four groups. The questions of the first group (the first two questions) were aimed at describing the respondents' collective profile. The questions of the second group (the following four questions, closed-ended type) were aimed at identifying the readiness of the ULF teacher to implement distance learning: The third group consisted of four open-ended questions that allow to find out the features of teachers' activities in the process of distance learning, its results and problems. With the help of the next four open-ended questions, was obtained information about the peculiarities of the activities of students in the process of distance learning of Ukrainian, its results and problems.

The answers obtained during the survey were processed to provide a maximum understanding of the teacher's readiness to implement distance learning of UFL, teachers' instrumental needs related to this activity and its results, and the needs of the teacher as a participant in the learning process.

\section{RESULTS}

\subsection{Readiness of the teacher to implement distance learning of $U F L$}

In the context of the introduction of computer information technology (CIT) in the higher education system, the question arises about the readiness of higher education institutions in general and teachers of UFL in particular to use them. Therefore, one of the aspects of the research is a study of the motivation of teachers to use information technology in distance learning. Before the forced transition of higher education institutions to distance learning due to the COVID-19 pandemic, eight people used online educational resources, i.e. $59 \%$ of the surveyed teachers. At the same time, five people (41\%) did not feel the need to master the CIT relevant professional competencies. However, at the time of the survey, i.e. after almost a year of teaching in a changing environment, 14 respondents $(100 \%)$ began to use online resources (Fig. 1). The formation of teachers' CIT skills and abilities was rapid.

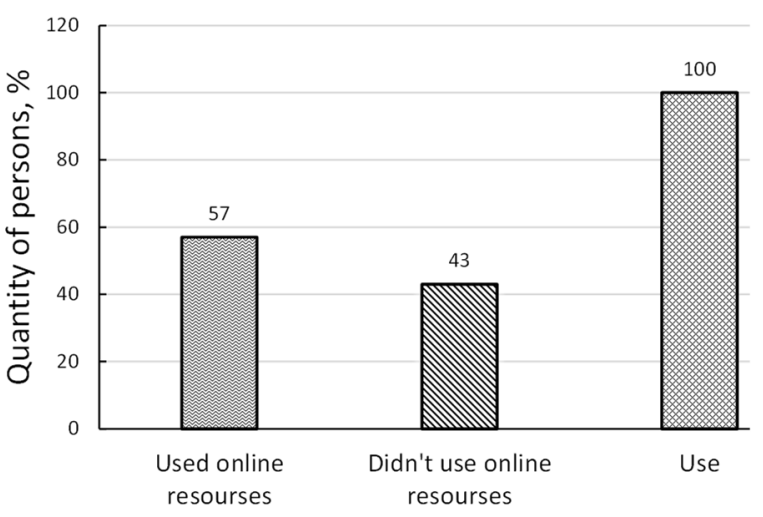

Figure 1 Use of online resources during the educational process before 2020 and in 2020-2021

At the same time, only $50 \%$ of respondents (7 persons) answered positively to the question about their plans to use online educational resources in their work with international students after the end of quarantine. Figure 2 illustrates the attitude of respondents to the possibilities of modern CIT in the educational process. $29 \%$ are planning to use it in future (four persons), and $14 \%$ of respondents (two persons) are unlikely to use them, and one person (7\%) is confident that this knowledge will not be needed at all.

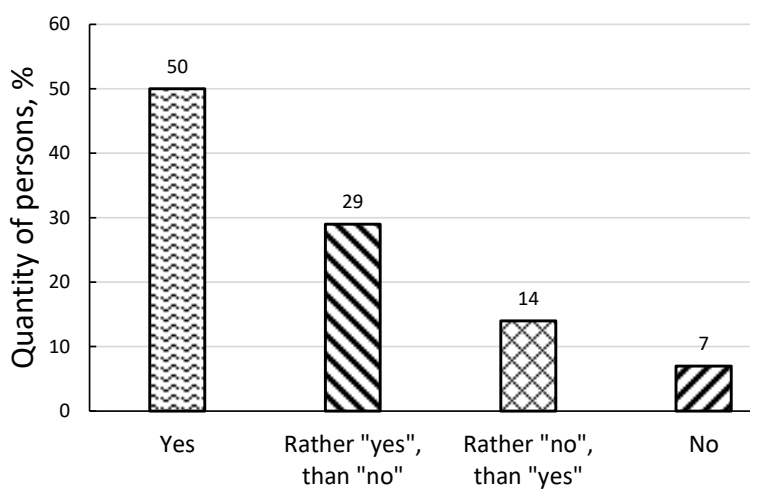

Figure 2 Use of online platforms and resources in the education process in the future

The full readiness of the education system for distance learning (online) was noted by two respondents (14\%). Five persons (36\%) partially agree with this, while $43 \%$ (6 persons) have the opposite opinion, and $7 \%$ (1 person) of respondents categorically deny such readiness (Fig. 3).

According to the results of the survey, the most often used for interaction with students are following: Zoom - 72\% (10 people); Moodle - $50 \%$ (7 persons); Google Meet - $43 \%$ (6 persons); Skype - $43 \%$ (6 persons); Viber - 72\% (10 people); Telegram - 36\% (5 persons); Google Classroom -29 \% (4 persons); 
UberConference - $7 \%$ (1 person); others - $14 \%$ (2 persons) (Fig. 4).

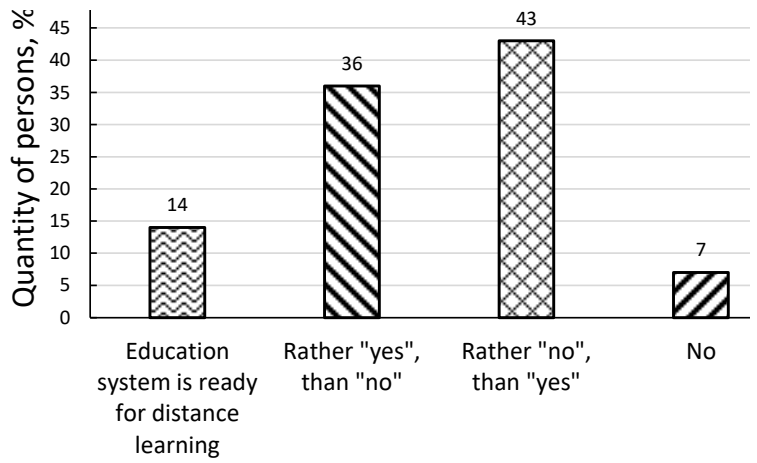

Figure 3 Readiness of the education system for distance learning

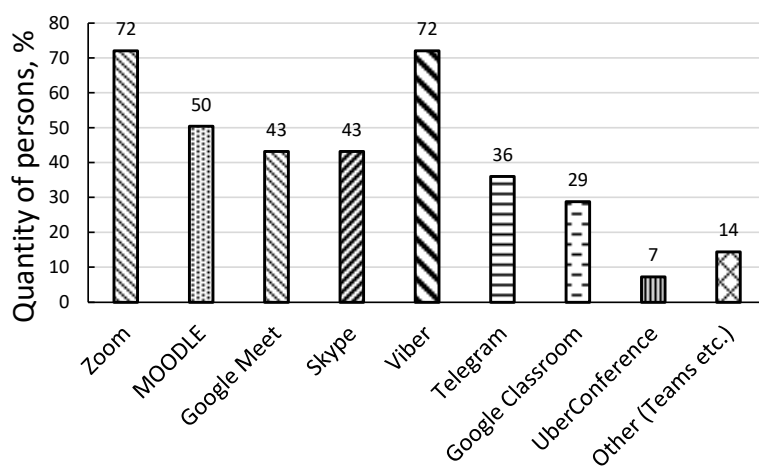

Figure 4 The most popular online platforms and resources for distant UFL learning

\subsection{Features of teachers' activity in the process of distance learning, its results, problems}

The purpose of the next block of questions was to determine the features of UFL teachers' activities, ways of presentation of the material and receiving feedback from the students, and problems that arose and complicated the work (Table 1).

According to the survey results, most teachers were either engaged in information searching about online educational platforms and resources or access to the platforms was provided to them by the university administration. A small number took the advice and help of colleagues.

Regarding the variants of organizing classes in distance learning, ranking found that the vast majority of respondents combine several ways of organizing classes. In particular, prevails conducting online video classes in combination with demonstrating tasks and necessary materials using Microsoft PowerPoint.
Next is posting materials on grammar, tasks for independent work, texts for reading, conversational topics on the online platform Moodle. This combination diversifies the work of students and protects against fatigue. In the last place - uploading of the materials to the online application Google Classroom, and the organization of classes and independent work of students using smartphones with Viber, Telegram messengers.

A not less important task in terms of distance learning was the choice of ways of uploading and assessing the completed works, because the control of learning outcomes is one of the main components of the educational process. Under the conditions of integration of full-time and distance learning, there were no problems with the organization of discipline current and final control. However, during the distance learning, intermediary control was carried out through the Internet: e-mail, forum, chats, e-conferences, Google Forms. The presented survey results show that among the variety of such tools, the most popular was sending completed assignments to the teacher by email. It can be assumed that an individual approach caused the choice of such a tool of interaction between teacher and student for the current assessment and control of the quality of knowledge. It should be noted that this format is the most time consuming both for preparation and assessment of tasks. Another widespread option is uploading to an educational platform for distance learning, and to a particular group on social networks.

The results of the analysis of current reasons complicating the transition to distance learning showed that the majority of respondents indicated a lack of precise regulation of the duration of online classes (uninterrupted work with computers, communication means) and insufficient skills and abilities to work with online educational resources.

One of the components of the UFL learning process is the student's independent cognitive activity, which provides freedom of actions and self-control. However, it may not always be successful in case of insufficient development of goal-setting and planning skills. It is especially noticeable during distance learning. The main condition of efficient use of online platforms and resources in the learning process is selfdiscipline, organization and students' responsibility. According to the survey results, the opinion about the necessity of high motivation and organizational skills of students as a condition of effective distance learning is supported by nine (64.3\%) respondents. 
Table 1. Results of UFL teachers' survey

\begin{tabular}{|c|c|}
\hline Question (variable) & Variants of obtained answers \\
\hline $\begin{array}{l}\text { Sources of information about } \\
\text { online educational platforms } \\
\text { and resources }\end{array}$ & $\begin{array}{l}\text { - Independent search for information about available platforms. } \\
\text { - Access to the platforms is provided by the university administration. } \\
\text { - Advice and help from colleagues. }\end{array}$ \\
\hline $\begin{array}{l}\text { Options (methods) for } \\
\text { organising classes during } \\
\text { distance learning }\end{array}$ & $\begin{array}{l}\text { - Classes with students via videoconferences combined with the demonstration of tasks } \\
\text { and necessary materials using Microsoft Power Point, placement of grammar material, } \\
\text { tasks for independent work, texts for reading, and conversational topics on the online } \\
\text { platform Moodle. } \\
\text { - Classes with students only via videoconferences. } \\
\text { - Posting advanced tasks, self-study of learning material on online resource combining } \\
\text { with video conferencing in Zoom, Google Meet, Skype, etc. } \\
\text { - Combining video lessons in Zoom, Google Meet, Skype with audio recordings of texts, } \\
\text { and vocabulary work. } \\
\text { - Placement of theoretical material on grammar, tasks for independent work, texts for } \\
\text { reading, conversational topics on the online platform MOODLE, Google Classroom } \\
\text { application, the organisation of students' independent work. } \\
\text { - Classes with the use of smartphones via Viber, Telegram, WhatsApp messengers. }\end{array}$ \\
\hline $\begin{array}{l}\text { Methods of uploading and } \\
\text { assessment of the performed } \\
\text { works }\end{array}$ & $\begin{array}{l}\text { - Sending of completed written assignments by e-mail. } \\
\text { - Uploading of completed written tasks to the Moodle platform, Google Classroom } \\
\text { application. } \\
\text { - Sending of written tasks of students to a particular group in social networks. } \\
\text { - Sending of audio recordings of completed tasks, conversational topics, reading of the } \\
\text { texts and its retelling, new words translation on messengers Viber, Telegram, WhatsApp. } \\
\text { - Online checking of tasks during video conferences via Zoom, Google Meets, Skype. } \\
\text { - Sending of a copybook photo with the completed tasks to Viber, Telegram. } \\
\text { - Written work is not provided. }\end{array}$ \\
\hline $\begin{array}{l}\text { Factors complicating the } \\
\text { transition to distance } \\
\text { learning of UFL }\end{array}$ & $\begin{array}{l}\text { - Lack of precise regulation on the duration of online classes for students (uninterrupted } \\
\text { work with a computer, means of communication). } \\
\text { - Insufficient skills and abilities to work with online educational resources. } \\
\text { - Low motivation and self-organisation of students. } \\
\text { - High complexity (preparation requires much more time, material costs for connection, } \\
\text { Internet, communication means upgrades). } \\
\text { - Lack of teacher's motivation. } \\
\text { - Psychological tension. } \\
\text { - Difficulties in choosing the optimal educational platform for classes. } \\
\text { - Lack of "live (face-to-face) communication" with students. }\end{array}$ \\
\hline
\end{tabular}

Among the reasons that complicate distance learning, thirteen respondents $(92.9 \%)$ indicated high workload and complexity (training requires much more time, material costs for Internet connection, upgrading of communication means). To ensure the proper quality of the educational process, preparation for online classes takes much more time than for classroom classes. It was necessary to master modern communication technologies and adapt to the new teaching process in a short period of time, and the number of stressors has increased. In the survey, ten respondents $(71.4 \%)$ also indicated a significant, in their opinion, the overload of students with educational material.

Psychological stress, insufficient skills and abilities to work with online educational resources and difficulties in choosing the optimal educational platform for classes were also mentioned by the respondents among the reasons that complicate the transition to distant learning of UFL. As a significant factor of learning process complication, four pedagogues $(28.6 \%)$ named the lack of live contact between teachers and students.

\subsection{Features of the students' activities in the process of distance learning of UFL, its challenges}

This block of questions made it possible to find out the peculiarities of the students' activities from the point of view of teachers, the difficulties students experienced during distance learning and motivational factors that increase the effectiveness of the educational process (Table 2).

The education of international students objectively has specific features. Taking them into account will help 
the teacher to improve the quality of the educational process. So, during the work with international students, difficulties unavoidably arise. They are not typical for teachers of the Ukrainian language as a native language. Analyzing the problematic aspects that arise in the process of UFL learning in distant mode, all variants of answers were divided into two groups - technical and motivational factors.

\section{Table 2. Analysis of students' activity}

\begin{tabular}{|c|c|}
\hline Question (variable) & Variants of obtained answers \\
\hline $\begin{array}{lr}\text { Difficulties } & \text { faced by } \\
\text { students } & \text { during } \\
\text { distance } & \text { learning } \\
\text { UFL } & \end{array}$ & $\begin{array}{l}\text { Technical factors: } \\
\text { - Absence of technical means } \\
\text { (computer, tablet, phone, } \\
\text { webcam). } \\
\text { - Students do not have access to } \\
\text { the Internet in the dormitory or } \\
\text { the apartment. } \\
\text { - Lack of skills and abilities to } \\
\text { work with online educational } \\
\text { resources. } \\
\text { Motivational factors: } \\
\text { - Lack of direct (face-to-face) } \\
\text { communication with the teacher } \\
\text { and students' communication } \\
\text { with each other. } \\
\text { - Lack of motivation to the } \\
\text { online work. }\end{array}$ \\
\hline 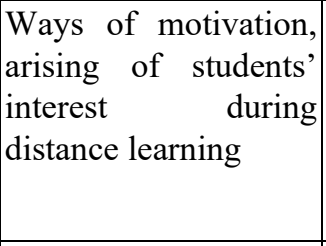 & $\begin{array}{l}\text { - Appliance of interactive } \\
\text { methods and elements of games. } \\
\text { - Use of texts about Ukrainian } \\
\text { traditions, holidays. } \\
\text { - Audio recordings of Ukrainian } \\
\text { poetry. }\end{array}$ \\
\hline $\begin{array}{l}\text { Opportunities for } \\
\text { students } \\
\text { communicate with the } \\
\text { teacher and with each } \\
\text { other }\end{array}$ & $\begin{array}{l}\text { - Use of messengers Viber, } \\
\text { Telegram, WhatsApp. } \\
\text { - Videoconferencing via Zoom, } \\
\text { Google Meet, Skype. }\end{array}$ \\
\hline $\mid \begin{array}{lr}\text { Opportunities } & \text { for } \\
\text { acquaintance } & \text { with } \\
\text { authentic speakers }\end{array}$ & $\begin{array}{l}\text { - Creating a list of links with } \\
\text { audio materials in Ukrainian } \\
\text { (songs, information programs). } \\
\text { - Creating a list of links with } \\
\text { videos in Ukrainian (movies, } \\
\text { entertainment programs). } \\
\text { - Communication with native } \\
\text { speakers of the Ukrainian } \\
\text { language. }\end{array}$ \\
\hline
\end{tabular}

Analysis of the respondents' answers about the difficulties students faced during learning UFL in a distant mode, in particular technical, showed that the majority of respondents $(57 \%-8$ persons) indicate the impossibility of connecting students to online classes due to lack of technical devices (computer, tablet, phone, webcam. Teachers have to keep in mind that some students have only smartphones of outdated models, whose functions are limited. Also, among the most topical issues is the lack of students' access to the Internet at home ( $43 \%-6$ persons). There were also problems with providing teachers with the necessary equipment and means of communication. Some teachers $(29 \%-$ 4 persons) do not have the necessary technical devices to connect to online broadcasts. Three respondents (21\%) note the risk of education quality reducing due to the insufficient mastery of distance learning technologies by all participants in the educational process and its insufficient technical support. An essential component of ensuring the appropriate level of quality of educational services and rapid adaptation of teaching staff to the new model of the organization of the educational process in quarantine is certification training in the use of distance learning technologies.

The not less critical difficulty of distance learning respondents noted the lack of personal "live" contact of students with the teacher and with each other $(29 \%-$ 4 persons). In distance learning, it is either minimal or absent, which complicates the use of group and collective forms of work and mutual control. There are also some difficulties in organizing feedback between the participants of the educational process, as students and teachers underestimate such communication tools as Viber, Telegram, WhatsApp, video communication via Zoom, Google Meet, Skype, preferring the traditional way of communication by phone or face-to-face communication during extracurricular activities.

During distance learning without personal communication, connections and relationships are weakened, emotionality decreases, which teachers usually use in the classroom activities. It is more difficult for a teacher to establish contact with students. Furthermore, what is more important - distant mode of interaction dictates new requirements for the organization of an effective educational process that stimulates thinking, creativity, supports the initiative and develops competence.

One of the most important factors for successful distance learning of UFL is student motivation, as the emphasis has shifted to independent work. It requires concentration, perseverance, a desire to learn. In distance learning, many types of traditional motivation do not work as effectively as during face-to-face learning. However some, on the contrary, acquire special significance. Ways of motivation, arousal of interest of students during distance learning, which, according to respondents opinion, can help in the conditions of distance learning - is the use of game elements, the use of texts about Ukrainian traditions, holidays, audio recordings of Ukrainian songs and poetry. Modern students are not interested in the dry text of the textbook. Motivation requires the usage of interactive methods or storytelling (information provided through a story, parable). $14 \%$ of respondents ( 2 persons) point to the 
necessity of creation of a list of links to get acquainted with audio and video materials in the Ukrainian language (movies, songs, entertainment programs).

The survey also found out the teachers' attitude towards distance learning and its impact on the results of the educational process. 5 of 14 respondents expressed an unequivocally negative attitude. Example: "I believe that personal contact offline is much better for material learning and provides an opportunity to work on what students have not understood or missed". Three persons do not object the online learning, but have some wishes to the process organization. Example: "The remote form of work can be a bit inconvenient, but it is just worth getting used to". "Distance learning is not a copy of fulltime learning in the classroom and requires a new structure of the organization of the lesson - at least because the attention and fatigue in front of the computer work completely differently". The part of respondents (6 persons) are supporters of blended learning, i.e., a combination of classroom work and online learning. Example:" As practice has shown, there are no global problems, there is a lack of flexibility of teachers themselves."

\section{DISCUSSION}

Distance learning is a process of interactive cooperation of participants of the educational process using various multimedia technologies. It is believed that distance learning has relieved teachers. In fact, the educational process in the distant mode is more labourintensive, as it involves an individual approach. Teaching requires a more individualized process of materials development and takes much more time to prepare. There are also gaps in the legislative framework regarding distance learning, namely the accounting of teachers' work, the duration of online classes for students, and the sanitary and hygienic requirements for uninterrupted work with computers and other gadgets.

Before the global COVID-19 pandemic, students of the preparatory department had the opportunity to study UFL offline. However, from 2020 up to the beginning of 2021, training takes place in a blended mode - a combination of distant and full-time forms. Distance learning is organized via Moodle learning platform and the Google Meet, Zoom applications. Tools such as smartphones, tablets, laptops, desktops were used for this purpose.

Successful study of the UFL involves international students familiarizing with the Ukrainian traditions, culture and history; development of their ability to crosscultural interaction. It provides basic abilities and skills forming - the use of language as a cross-cultural interaction tool; awareness of the complexities of the Ukrainian language; ability to work with books, reference literature, dictionaries. The process of cross- cultural communicative activity has specifics traits, and it requires not only knowledge of the foreign language, but also knowledge of the culture of other nation. It realizes specific tasks, namely: educational - the formation of oral public speaking skills; developing dissemination of knowledge about the historical and cultural heritage of another state; educational - formation of a respectful attitude to the language, and to the culture of the nation whose language they study. Combining traditional methods, such as the explanatory-illustrative, reproductive, problem-solving, method of partial-search, research method with interactive methods, including project method and role-playing games is possible to activate and stimulate the cognitive activity of foreign students while learning UFL.

For many years, the grammar-translation method was the basis for teaching foreign languages and has lost its relevance. The need to introduce modern technologies into the educational process to improve the quality of education and intensify the independent work of students becomes clear. Working with information based on reading texts and watching videos in Ukrainian allows using Internet resources, expanding the content of the textbook with authentic and relevant information (recent world events (sports, cultural, etc.), texts of native speakers (movies, videos). The potential number of individual educational trajectories, in this case, is more significant than in traditional education. But not all texts from Internet resources are suitable directly for educational purposes.

A special role in online learning is played by web conferences, allowing all participants to lead an active polylogue with high didactic value. Listening and reading poems by T. Shevchenko and Lesya Ukrainka with the students of the preparatory department of KNUTD was organized. The event made a positive impact on the formation of motivation to study the UFL and vocabulary enrichment. It was conducted via online video conference and timed to the relevant calendar dates - the anniversaries of the birth and death of Taras Shevchenko and the 150-th anniversary of the birth of Lesya Ukrainka. For this purpose, audio recordings of poems in Ukrainian were used, and the students themselves read the poems. Translations of poems in Chinese, English, Arabic, and French were used to improve students' perception and understanding of the content.

Students of the preparatory department also together with Ukrainian language teachers, take part in conferences of different levels, where they speak about the peculiarities of education in their home countries, present their culture and national traditions. An International Conference "Dialogue of Cultures in the European Educational Space" is conducted in KNUTD. Participation is confirmed by joint publications of students with teachers [19]. This year the involvement of listeners and students in the conditions of distance 
learning is planned online. In this way, students enrich their vocabulary, form public speaking skills, and learn to join the discussion.

Motivation is the driving force of the subject's cognitive activity. However, in the education of international students it has some features that correlate with the results of the study [17]. To acquire the necessary professional skills, foreign students must fully enter into a Ukrainian communicative and cultural environment. This a priori foresees mastering the language of instruction and communication and, it would seem, does not require additional motivation. However, in practice, completely different factors that influence motivation are interlaced, starting with language and social isolation, as well as the formal attitude to the obtaining of higher education diplomas by international students. Most modern international students have gadgets and electronic translators that allow them to meet their household needs without making an effort to learn the language of another country. There is also a reluctance of international students to leave the zone of "language" comfort. They prefer to communicate with their compatriots. Difficulty in studying the phonetic and morphological-syntactic levels of the Ukrainian language and adaptation of foreigners in other cultural and social environments are the main negative factors that have an objective impact on the learning outcomes of international students.

In our opinion, possible demotivating factors during the distance learning of UFL are the initial low internal motivation of students. Distance learning is an unusual form of learning for them, lack of self-education experience, absence of direct live contact with peers during training, limited emotional stimulation of students by the teacher; habit of strict control, poor computer skills and knowledge of basic computer programs; absence of computer or access to the Internet due to living or social conditions.

Analysing the problems faced by respondents in the transition to online learning of UFL, it can be argued that distance learning is now understood not as a form of learning, but as a technology. Implementation of the technical component, namely the improvement of multimedia equipment, upgrading with the latest software, access to the Internet and communication channels - tasks that need to be solved. These problems concern not only the teaching of the UFL, but are overall characteristic of distance learning. In general, the results of the study are consistent with the conclusions of scientists on the use of mobile, e-learning [20], [21]. At the same time, the use of mobile phones and mobile applications, the effectiveness of which has been proven by S. Yorganci [22], and T. Brown and L. Mbati [23], seems insufficient.

An equally important issue is the retraining and certified training of teachers. In this regard, some problems arise. Teachers themselves do not fully understand their role in distance learning, as they believe that it is a process of transmitting e-learning materials via the Internet. However, without a teacher, training cannot be fully organized.

\section{CONCLUSIONS}

Thus, it can be argued that the availability of the necessary electronic educational resources and technical means of learning and at the same time the formation of skills for their application, professional development of didactic and technical aspects of UFL distance learning create prerequisites for effective distance learning. This form of education gives all the opportunities to master different types of speech activity, forming communicative competence. But it is essential to understand that distance learning is not uncontrolled or unsystematic, and it will only benefit if adequately organized.

According to the results of the research, the following conclusions can be drawn:

1. Distance learning technology encourages teachers to rethink ways of knowledge transfer. The teacher must be able to develop organizational and methodological documentation, design individual and group learning trajectories, organize work with multimedia resources, create their own electronic resources. In this regard, there is a need to organize systematic work to improve teachers' professional skills in the use of modern learning technologies.

2. The use of electronic textbooks makes the process of forming language competence more flexible and will allow the teacher to apply innovative forms and technologies of teaching in practice.

3. Among the problems that students face when learning UFL, the following are highlighted: lack of technical means (computer, tablet, phone, webcam, etc.), Internet access in the dormitory and the apartment, insufficient level formation of skills and abilities of independent work and work with online educational resources and low level of self-organization.

4. Among the shortcomings UFL teachers when organizing distance learning often point to lack of clear regulations on the duration of online classes, insufficient skills and abilities to work with online educational resources, high complexity, psychological stress, difficulties in choosing the optimal educational platform for classes, lack of "live communication" with students.

\section{REFERENCES}

[1] O. Nitenko, Internationalization of Higher Education as Factor of the Development of University, Educological Discourse 2(10) (2015) 
205-216.

https://od.kubg.edu.ua/index.php/journal/article/vie $\mathrm{w} / 249$

[2] J. Knight, Internationalization: A Decade of Changes and Challenges, International Higher

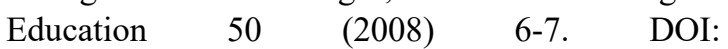
https://doi.org/10.6017/ihe.2008.50.8001

[3] Ministry of Education and Science of Ukraine, State Enterprise "Ukrainian State Centre for International Education”, 2021. https://cutt.ly/lkQZisQ

[4] B.T. Wang, Designing mobile apps for English vocabulary learning, International Journal of Information and Education Technology 7(4) (2017) 279-283.

DOI: https://doi.org/10.18178/ijiet.2017.7.4.881

[5] A. Lieungnapar, Language Learning Applications for the Education 4.0, IOSR Journal of Humanities and Social Science (IOSR-JHSS) 24 (02) (2019) 22-26. DOI: https://doi.org/10.9790/08372402092226

[6] M. Habbash, Learning English vocabulary using mobile phones: Saudi Arabian EFL instructors in focus, European Scientific Journal 11 (35) (2015) 446-457.

https://eujournal.org/index.php/esj/article/downloa d/6808/6535

[7] N. Gamlo, Saudi EFL Learners' Perceptions of the Benefits of ICT Integration into English Learning, Studies in English Language Teaching 7(2) (2019) 163-173.

DOI: https://doi.org/10.22158/selt.v7n2p163

[8] O. Suwantarathip, W. Orawiwatnakul, Using mobile-assisted exercises to support students' vocabulary skill development, The Turkish Online Journal of Educational Technology 14 (1) (2015) 163-171.

http://files.eric.ed.gov/fulltext/EJ1057347.pdf

[9] B. Zou, J. Li, Exploring mobile apps for English language teaching and learning, in: F. Helm, L. Bradley, M. Guarda, S. Thouësny (Eds.), Proceedings of the 2015 EUROCALL Conference, Padova, Italy, Dublin, 2015, pp. 564-568. DOI: https://doi.org/10.14705/rpnet.2015.000394

[10] N. Abuzahra, M. Farrah, S. Zalloum, Using cartoon in language classroom from a constructivist point of view, Arab World English Journal (AWEJ) Special Issue on CALL 3 (2016) 229-245. DOI: https://doi.org/10.2139/ssrn.2822995

[11] T. Bahrani, T.S. Sim, Audiovisual news, cartoons, and films as sources of authentic language input and language proficiency enhancement, The Turkish
Online Journal of Educational Technology 11(4) (2012) 229-245.

[12] T. Bahrani, T. Sim, M. Nekoueizadeh, Second Language Acquisition in Informal Setting, Theory and Practice in Language Studies 4(8) (2014) 17141723. DOI: https://doi.org/10.4304/tpls.4.8.17141723

[13] Z.O. Pakholok, L.P. Myroniuk, Methods of treatment of Google Slides cloud processing services and Sites to make homepage presentations and placing them on the site in the course "Ukrainian language as foreign", Computerintegrated technologies: education, science, production $38 \quad(2020) \quad 51-58$. DOI: https://doi.org/10.36910/6775-2524-0560-202038-09

[14] L. Cherednyk, A. Bolotnikova, Ukrainian language as a Foreign in the aspect of in the aspect of intercultural communication, Humanities science current issues: interuniversity collection of scientific works of young scientists of Drohobych State Pedagogical University named after Ivan Franko 31 (4) (2020) 221-226. DOI: https://doi.org/10.24919/2308-4863.4/31.214384

[15] L.P. Sheremeta, Formation of student's (medical specialties) dialogic speaking skills while studying the Ukrainian language as a foreign, Medical Education 3 (2019) 103-107. DOI: https://doi.org/10.11603/me.24145998.2019.3.10651

[16] L.P. Bohoslavets, Propaedeutic course of the Ukrainian language of foreign students at a technical university, Scientific Journal Virtus 20 (P.1) (2018) 79-82. https://er.knutd.edu.ua/handle/123456789/9043

[17] S.F. AlMunawwarah, Students' motivation in EFL learning, TELL-US Journal 4(2) (2018) 108-119. DOI: https://doi.org/10.22202/tus.2018.v4i2.2779

[18] A. Kolodiazhna, O. Mushkudiani, Foreign students of preparatory faculties' motivation as for the formation of foreign language communicative competence, Scientific Letters of Academic Society of Michal Baludansky 6(2A) (2018) 81-83. https://er.knutd.edu.ua/handle/123456789/10534

[19] Dialogue of cultures in the European educational space, Proceedings of the IV international conference, Kyiv, May 14-th, 2019. Kyiv, KNUTD, 2019, 215 p. https://cutt.ly/CvUAYVw

[20] C. Pribeanu, G. Gorghiu, V. Lamanauskas, V. Slekiene, Use of mobile technology in the teaching/learning process - opportunities and 
barriers, eLearning sustainment for never-ending learning (The 16th International Scientific Conference eLearning and Software for Education Bucharest, April 23-24, 2020) Bucharest: Carol I National Defence University Publishing House, vol. 1, 2020, pp. 376-383. DOI: https://doi.org/10.12753/2066-026X-20-049

[21] L. Dias, A. Victor, Teaching and learning with mobile devices in the 21st-century digital world: Benefits and challenges, European Journal of Multidisciplinary Studies 2(5) (2017) 339-344. DOI: http://doi.org/10.26417/ejms.v5i1.p339-344

[22] S. Yorganci, Investigating Students' Self-Efficacy and Attitudes Towards the Use of Mobile Learning, Journal of Education and Practice 8(6) (2017) 181185. https://cutt.ly/bk2AgwW

[23] T.H. Brown, L.S. Mbati, Mobile Learning: Moving Past the Myths and Embracing the Opportunities, International Review of Research in Open and Distance Learning 16(2) (2015) 115-134. DOI: https://doi.org/10.19173/irrodl.v16i2.2071 